\title{
BMJ Open Investigating equalisation of health inequalities during adolescence in four low-income and middle-income countries: an analysis of the Young Lives cohort study
}

Joseph L Ward, Russell M Viner

To cite: Ward JL, Viner RM. Investigating equalisation of health inequalities during adolescence in four low-income and middle-income countries: an analysis of the Young Lives cohort study. BMJ Open 2018;8:e022114. doi:10.1136/ bmjopen-2018-022114

- Prepublication history and additional materials for this paper are available online. To view these files, please visit the journal online (http://dx.doi org/10.1136/bmjopen-2018022114).

Received 5 February 2018 Revised 11 June 2018 Accepted 31 July 2018

\section{ABSTRACT}

Objective To investigate if socioeconomic gradients in health reduce during adolescence (the equalisation hypothesis) in four low-income and middle-income countries (LMIC).

Setting Analysis of the Young Lives Study cohorts in Ethiopia, Peru, Vietnam and India.

Participants A total of 3395 participants (across the four cohorts) aged 6-10 years at enrolment and followed up for 11 years.

Outcomes measured Change in income-related health inequalities from mid-childhood to late adolescence. Socioeconomic status was determined by wealth index quartile. The health indicators included were self-reported health, injuries in the previous 4 years, presence of longterm health problems, low mood, alcohol use, overweight/ obesity, thinness and stunting. The relative risk of each adverse health outcome between highest and lowest wealth index quartile were compared across four waves of the study within each country.

Results We found steep socioeconomic gradients across multiple health indicators in all four countries. Socioeconomic gradients remained similar across all waves of the study, with no significant decrease during adolescence.

Conclusion We found no consistent evidence of equalisation for income-related health inequalities in youth in these LMIC. Socioeconomic gradients for health in these cohorts appear to persist and be equally damaging across the early life course and during adolescence.

\section{INTRODUCTION}

Socioeconomic status (SES) is a strong predictor of health. ${ }^{12}$ To be born and grow up in poverty shortens life expectancy and increases the risk of illness and injury, but health inequalities also exist at all levels of income. ${ }^{2}$ Although there is evidence that social health gradients persist throughout the life course, ${ }^{3}$ it has been suggested that they may reduce during adolescence (ie, there is 'equalisation' in outcomes by SES in young people). ${ }^{4}$ Such equalisation has been shown in
Strengths and limitations of this study

- This is the first systematic investigation of whether socioeconomic inequalities in health reduce during adolescence (the equalisation hypothesis) in low-income and middle-income countries (LMIC), where $90 \%$ of the world's young people live.

- We explored socioeconomic gradients from mid-childhood to late adolescence in eight health outcomes within four LMIC

- We used the Young Lives wealth index to assess socioeconomic status; a composite measure of housing quality, access to services and country-specific consumer durables.

- Owing to the limits of the sample size in each country, we did not stratify our analysis by sex.

social gradients for multiple health outcomes including mortality, ${ }^{5-7}$ parent-rated health and long-standing illness, ${ }^{8}$ mental health and psychological well-being, ${ }^{9}$ obesity, ${ }^{10}$ general health and accidents. ${ }^{11}$

Multiple mechanisms have been proposed to explain the apparent reduction in health inequalities in young people compared with those in young children and adults. The increasing importance of youth culture and peer relationships during adolescence, and opportunities for social mixing in schools, may mediate the influence of family SES on health. ${ }^{59}$ Further, the increase in autonomy and risk taking in young people, which may have multiple adverse health outcomes, has been shown to be less closely associated with parental social class than with peer group identification, particularly for substance misuse. ${ }^{12}$

Health outcomes and behaviours during adolescence predict future adult health and that of the next generation. ${ }^{13}$ It is vital to understand how social factors influence 
outcomes in this age group, ${ }^{14}$ particularly within low-income and middle-income countries (LMIC), where $90 \%$ of young people live. ${ }^{15}$ Yet the evidence for equalisation has come almost exclusively from high-income settings, and an analysis of how the strength of health inequalities may change during adolescence in LMIC is lacking. It can be hypothesised that patterns of health inequalities during adolescence in LMIC may differ from high-income settings, as structural determinants of health are heavily influenced by country income group.

This is the first study of how social gradients in health outcomes vary during the early life course in LMIC. Longitudinal cohort studies of adolescent health are limited in LMIC, ${ }^{16}$ but the recent publication of health outcomes within a large cohort of young people in four LMICs, with longitudinal data on variables for SES, has provided the opportunity for this study.

\section{METHODS}

Data were derived from the Young Lives study, an international panel study of child health and social outcomes following children and young people in four LMIC: Ethiopia, India (Andhra Pradesh), Peru and Vietnam. ${ }^{17}$ Data are publicly available at their website (http://www.younglives.org.uk) and have been accessed on 5 July 2016. As the Young Lives Study aimed to document childhood poverty, deprived populations were over-represented in the sampling strategy. Twenty sentinel sites within each country were selected non-randomly, with richer areas excluded. Households with children within the right age group were then randomly sampled from each sentinel site. ${ }^{18}$ Full details of the methods used within the study, participants recruited and details of attrition rates are available at Young Lives' website (http:/ /www.younglives. org.uk).

We used data from four rounds of the older child cohort (2002, 2006, 2009 and 2013). Participants were in mid-childhood in round 1 (age 6-10 years), early adolescence in round 2 (10-15 years), mid-adolescence in round 3 (14-17 years) and late adolescence/young adulthood in round 4 (17-22 years). Data were available on 3395 individuals across the four countries involved in the study.

\section{HEALTH INDICATORS}

We selected health indicators if they were present in a comparable form across multiple waves of the study and were common to the four countries included. All indicators were defined as binary variables using clinically relevant thresholds, taking the value 1 if an adverse health outcome/behaviour was present and 0 if not. All health outcomes were reported by the children/young people themselves, except the presence of a long-term illness which was reported by the primary caregiver.

\section{General health and injuries}

1. Self-reported health: Poor health was defined as answering 'very poor', 'poor' or 'average' to 'In general, would you say your health is very poor, poor, average, good or very good.'

2. Long-term health: The presence of a long-term illness was defined as answering yes to 'Does [CHILD] have any long-term health problems which affect how they play/attend school or work/other' in round 1 and 'Does [CHILD] have any long-term health problems that affect their daily life?' in round 2.

3. Injuries: Injuries were defined as answering 'yes' to: 'Since we visited (4years ago) have you been seriously injured?'

\section{Psychological well-being}

1. Low mood: Low mood was defined as answering 'certainly true' or 'a little true' to the question 'You are often unhappy, downhearted or tearful.'

\section{Substance misuse}

1. Alcohol: No alcohol use was defined as answering 'I never drink alcohol' to 'How often do you usually drink alcohol? I never drink alcohol; everyday; at least once a week; at least once a month; only on special occasions; hardly ever.'

2. Smoking: Data on cigarette smoking were only available in multiple rounds of the study in two countries, and were therefore not included in our analysis.

\section{Nutrition}

Poor nutrition was defined according to definitions provided by WHO (available at http://www.who.int/ childgrowth/en/).

1. Overweight or obesity: Defined as having a body mass index (BMI) more than $1 \mathrm{SD}$ above the WHO growth reference median.

2. Thinness: Defined as having a BMI-for-age more than 2 SD below the WHO growth reference median.

3. Stunting: Defined as having a height-for-age more than $2 \mathrm{SD}$ below the WHO growth reference median.

\section{SOCIOECONOMIC STATUS}

We used the wealth index provided by the Young Lives study to assess SES of participants. The Young Lives wealth index is composed of three equally weighted domains: housing quality, access to services and consumer durables. The housing quality index includes the following items: a score for crowding (number of rooms per household members; one is the maximum recordable value), and dummy variables for the suitability of the material used for the walls, roof and floor of the dwelling. The access to services index is derived from dummy variables for access to electricity, access to safe drinking water, access to sanitation and access to cooking fuels. The consumable durables index is composed of a list of dummy variables for household items specific to each country. ${ }^{19}$ Each item within a domain is scored $0-1$, and the average of these is 


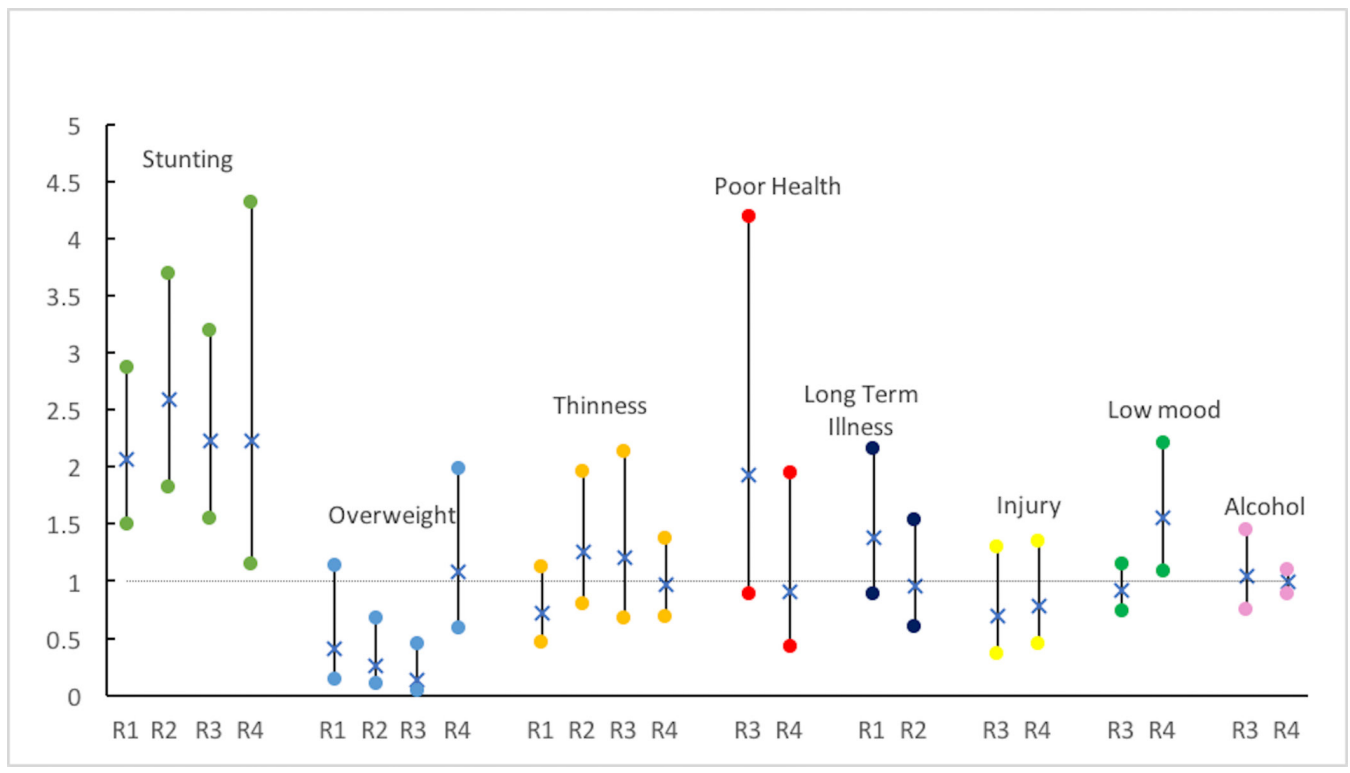

Figure 1 Relative risk of health outcome (lowest wealth quartile compared with highest) by round in Vietnam.

used as the domain score; the wealth index is an average of these three domains and ranges from 0 (low SES) to 1 (high SES). ${ }^{20}$

\section{PROCEDURES}

To assess the presence of social gradients in health, we recorded the proportion of participants presenting with each outcome by wealth quartile, and calculated the relative risk (RR) of each among the lowest wealth index quartile compared with the highest. To assess for change in social gradients through adolescence, these RR estimates with $95 \%$ CIs were compared across each wave of the study, where data were available. If the CI in one round of the study did not overlap the estimate for any previous or subsequent round, the social gradient was considered to differ between rounds for that health outcome. All analyses were performed in Stata V.14 (StataCorp).

\section{PATIENT AND PUBLIC INVOLVEMENT}

Patients were not directly involved in this analysis.

\section{RESULTS}

In total (across all four countries), data were available for 3395 participants in round 1, 3385 participants in round 2, 3357 participants in round 3 and 3356 participants in round 4 . The RR of each health outcome among participants in the lowest wealth index quartile compared with the highest wealth index quartile by country and round are shown in figures $1-4$. The number of participants with

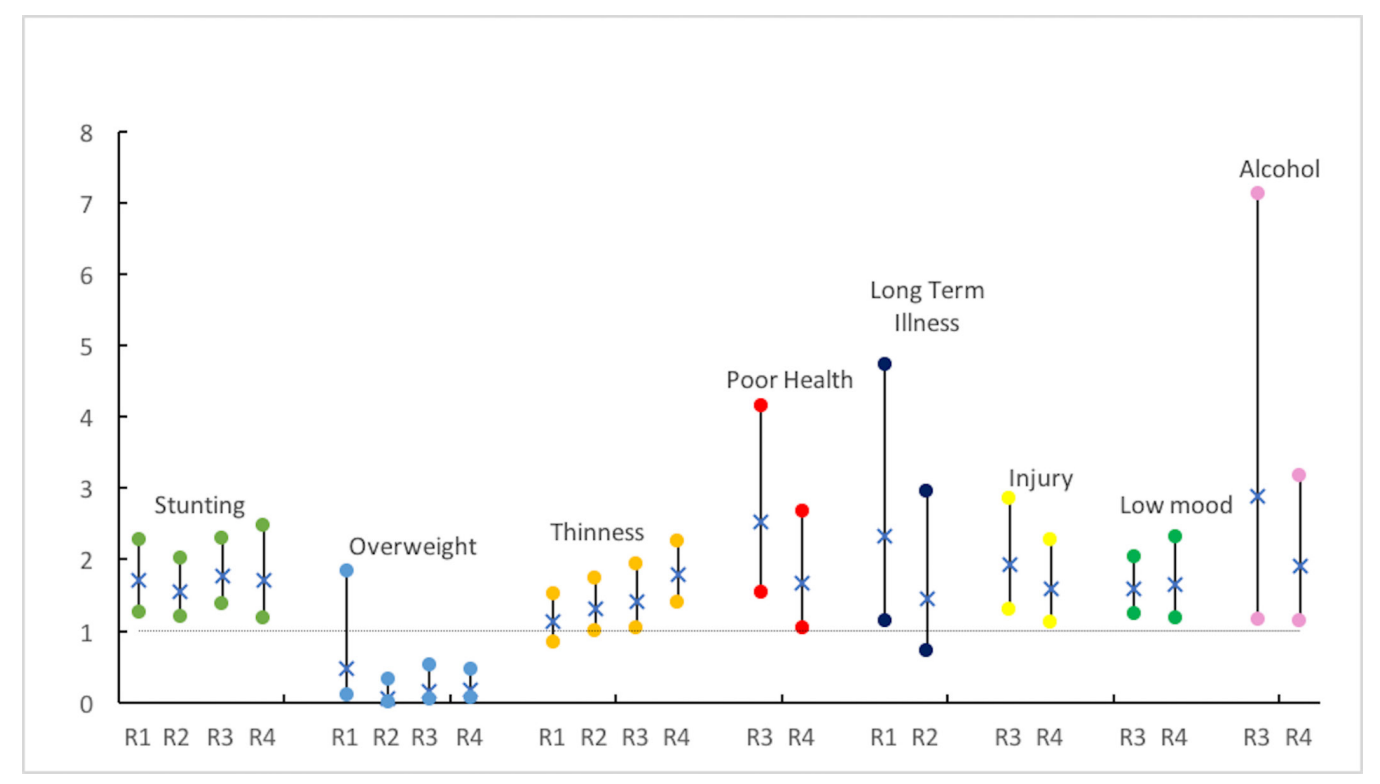

Figure 2 Relative risk of health outcome (lowest wealth quartile compared with highest) by round in India. 


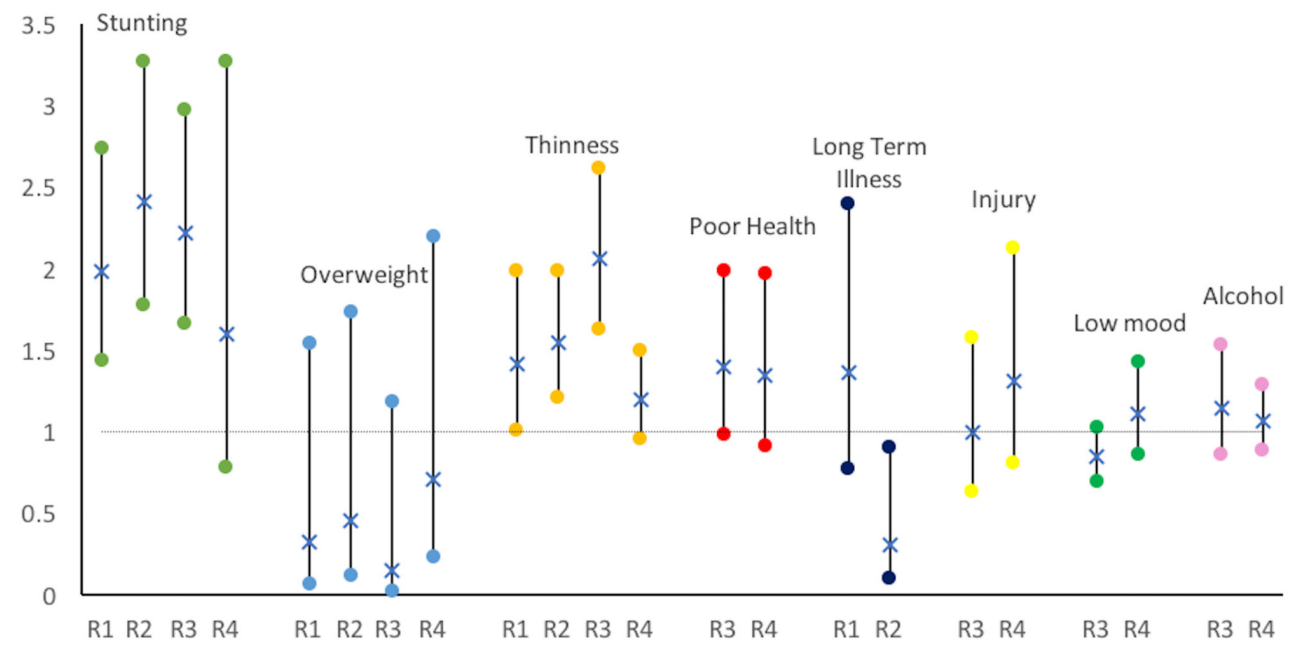

Figure 3 Relative risk of health outcome (lowest wealth quartile compared with highest) by round in Ethiopia.

data on SES by country, round and sex, and the prevalence of each health outcome by country, round and wealth index quartile is shown in the online supplementary appendix 1.

Social gradients, indicated by significant increases in RR estimates (lowest wealth quartile compared with highest wealth quartile) in any round of the study where data were available, were seen for poor health (India and Peru), long-term illness (India), injury in the last 4 years (India), low mood (India and Vietnam), alcohol (India), stunting (all countries) and thinness (India and Ethiopia). The RR of obesity was reduced among the lowest wealth quartile compared with the highest (a reversed social gradient) in all countries except for Ethiopia. We also found a reversed social gradient for drinking alcohol in Peru and long-term illness in Ethiopia.
There was no consistent pattern of increases or reductions in RR across rounds of the study for any variable. The only variables with apparent reduction in the social gradient in late adolescence (round 4) compared with earlier rounds were overweight/obesity in Vietnam and Peru and thinness in Ethiopia. In contrast, a number of health outcomes showed a significant increase or decrease in RR by wealth quartile in one round of the study, with no difference between lowest and highest wealth quartile in previous or subsequent rounds (although CIs did overlap between rounds in these examples). The RR of poor health in Peru, long-term illness in India and stunting in Ethiopia were increased among the lowest wealth index quartile compared with the highest in round 3 , with no significant differences found in round 4 (late adolescence). The RR of low mood was not significantly

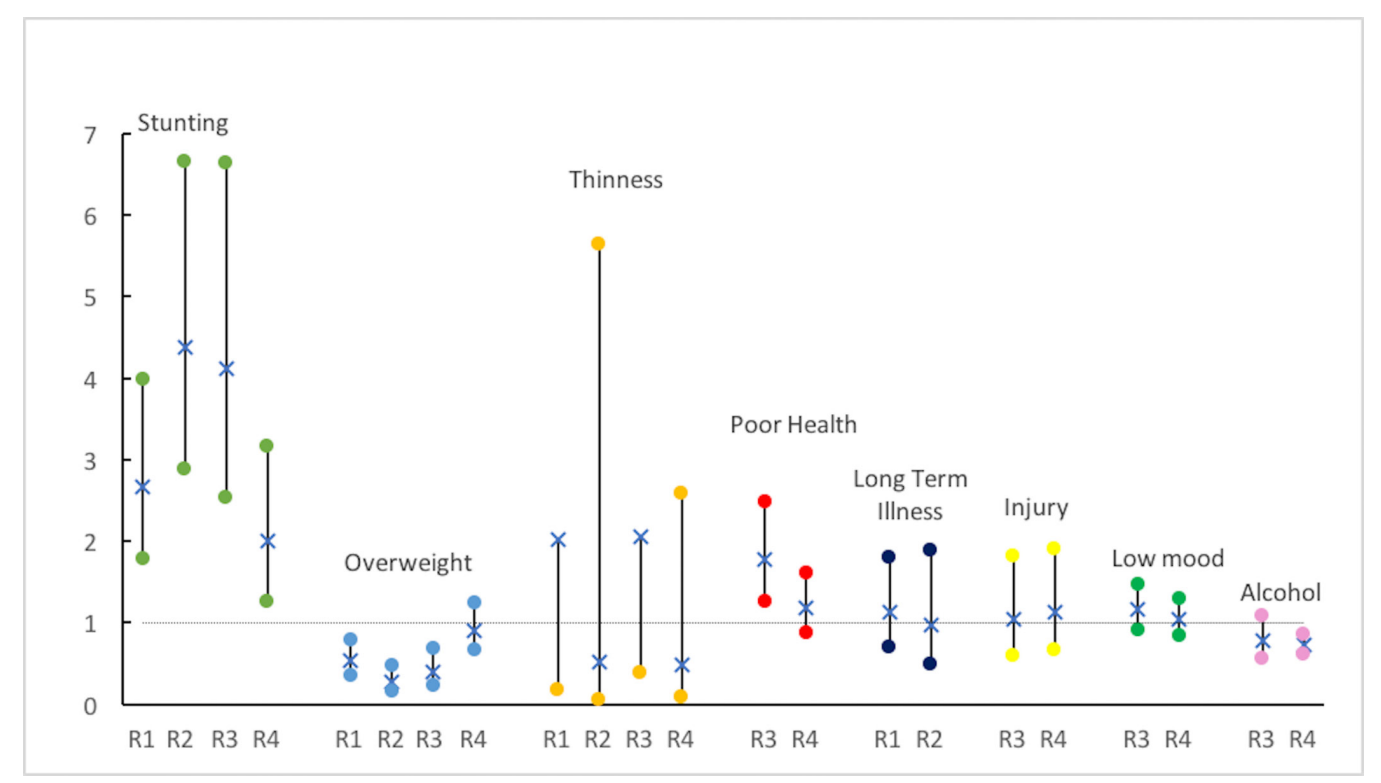

Figure 4 Relative risk of health outcome (lowest wealth quartile compared with highest) by round in Peru. 
different between lowest and highest wealth quartile in round 3 in Vietnam, but was increased in round 4. Similarly, RR of obesity/overweight in India showed no social health gradient in round 1 , but was significantly reduced in rounds 2, 3 and 4, and the RR of thinness was significantly increased in rounds 3 and 4 in India, but no difference was found in rounds 1 and 2.

\section{DISCUSSION}

We found very limited evidence for a weakening in the association between income status and risk of poor health across adolescence for some outcomes (overweight/ obesity in Vietnam and Peru, thinness in Ethiopia). However, there was no consistent pattern of equalisation during adolescence. Indeed, for some outcomes (eg, thinness in India), there appeared to be an increase in health inequalities as age increased.

\section{Comparison with the literature}

The evidence for a reduction in health inequalities during adolescence has come almost exclusively from high-income countries as noted previously; to our knowledge, there have been no comparable studies of equalisation in low-income and middle-income settings. Although we did find isolated examples of reduced health inequalities during late adolescence, our findings were broadly consistent with previous research illustrating persistent social health gradients in young people. Emerson et al found SES to be associated with multiple adverse health outcomes using data from 10438 children aged between 5 and 15 years, and little evidence for a reduction in social gradients in adolescence. ${ }^{21}$ The importance of health inequalities during adolescence is further supported by studies of self-reported health in Europe and North America $^{22}$ and ecological analyses from countries across the income spectrum. ${ }^{14}$

In describing the equalisation hypothesis, West and Sweeting argue that patterns of childhood health inequalities are likely to persist during adolescence for chronic medical problems and health potential (health status). In contrast, adverse outcomes which emerge during adolescence (health state) will be less closely aligned to family SES, due to the increasing influence of peer relationships on these outcomes, and the opportunities for social mixing in school. ${ }^{11}$ Emerson et al also highlight that negative health gradients are greater for more severe disorders, and that reverse health gradients tend to be restricted to self-reported indicators for health. ${ }^{21}$ Among the health indicators we were able to include in our analysis, we would therefore expect subjectively assessed health, low mood and injury to be the more likely candidates for equalisation, but we found no evidence to support this in our findings.

There appeared to be a reduction in health inequalities in some nutritional outcomes in our analysis, including obesity. Using data from the health survey for England, Vallejo-Torres et al found weaker associations in late adolescence between SES and obesity, when compared with younger children or older adults. ${ }^{10}$ However, comparability with our analysis is problematic, as the pattern of health inequalities for obesity was reversed, with an increased risk of obesity among higher socioeconomic groups consistent with previous studies from LMIC. ${ }^{23}$

Findings from the 2013/2014 Health Behaviour in School-age Children survey (which includes some middle-income countries) demonstrate a complex picture of health inequalities during adolescence, with consistent social gradients in health outcomes but weaker associations in health risk behaviours (early sexual intercourse and substance misuse). ${ }^{24}$ The relationship between alcohol consumption and SES has been shown to be weak during adolescence in multiple previous studies in high-income settings, ${ }^{25}$ and it has been suggested that peer social status may be a stronger determinant to risk behaviours such as alcohol consumption than family social status. ${ }^{25}$ We find only limited support for this in our analysis. In Ethiopia and Vietnam, we found no association between alcohol and SES; yet in India, we found risk of alcohol consumption to be higher among the poorer participants, and in Peru we found the reverse, although only among older adolescents.

\section{Strengths and limitations}

This is the first systematic examination of equalisation in longitudinal cohorts from LMIC. We included cohorts of between 900 and 1000 participants across four very different settings. We examined patterns of social gradients in health across eight outcomes which included physical, psychological and nutritional indicators, and compared social health gradients over an 11-year period from mid-childhood to early adulthood.

There were a number of limitations to our study. Owing to the limits of the sample size in each country, we did not stratify our analysis by sex. There is some evidence that social inequalities in health among females may be more profound than in males ${ }^{26}$ although the evidence for this is mixed. ${ }^{27}$ We used clinically important thresholds to produce dichotomous variables for each health outcome examined, but this may have missed more subtle changes in the risk of poor health by SES. For a number of health outcomes, we were only able to compare social gradients between early/mid adolescence and late adolescence/ early adulthood, and we may have missed the reduction in gradients by age as a result.

There are also acknowledged difficulties in defining SES in young people. We used the Young Lives wealth index-a composite measure of housing quality, access to services and country-specific consumer durables, designed for longitudinal analyses of SES within each cohort. Asset indices such as this have a greater resistance to seasonal fluctuations in income and expenditure compared with other measures, but have also been criticised for capturing urban social stratification better than in rural settings and for not allowing betweencountry comparisons. ${ }^{28}$ Our results may have differed 
using alternative proxies for SES such as parental occupation, educational attainment, consumption expenditure, household income or subjective measures (although these also have well-described limitations). ${ }^{21} 28$

\section{Meaning and mechanisms}

Although the risk of adverse health was increased among young people with lower SES for multiple health outcomes examined across all four countries, we did not find significant social gradients for several indicators, and this varied considerably by country. Whereas there were strong health inequalities in India for most outcomes, in Vietnam only the risk of stunting, low mood and obesity varied by SES. The absence of social gradients for some outcomes may reflect limitations in the power of the study to detect significant differences in risk by wealth index quartile. Further, the over-representation of deprived participants, and reduced wealth inequality within the Young Lives cohorts compared with national levels, ${ }^{29}$ may have limited the effect of SES for some outcomes. Differences between countries may be partially explained by substantial variation in the distribution of wealth index, with Vietnam having the highest overall level, with the least variability. ${ }^{19}$ We should also consider whether the absence of social gradients in some outcomes may indicate evidence for equalisation which would be revealed had we been able to follow-up participants over a longer period. However, Vallejo-Torres et al found equalisation to arise when comparing children aged 12-15years with those aged $16-19$ years, ${ }^{10}$ age groups which were included in our analysis for most outcomes.

Our findings of reversed social gradients in obesity are consistent with previous studies in LMIC. ${ }^{23}$ This has been explained by continued food scarcity and increased manual work among the poor in these settings, and increased access to excess food with lower levels of manual labour among the more wealthy, combined with a larger body size being associated with a positive sign of status in some countries. ${ }^{23}$ The reversed social health gradient in the risk of long-term ill health in Ethiopia in early adolescence (10-14years old) is more difficult to explain, but may reflect some reporting bias; as those with higher SES have greater access to health services, they may be more likely to be diagnosed with long-term conditions.

The lack of consistent evidence for equalisation in our analysis has multiple possible explanations. The evidence supporting reduced health gradients during adolescence is limited in high-income countries and has been contested, ${ }^{30}$ and our finding does not support the notion of equalisation. There may also be factors specific to LMIC to consider. Structural social determinants during adolescence have been shown to differ by country income group, ${ }^{14} 31$ and thus the drivers of equalisation may not be present or may appear at different timings to those in high-income countries. The level of autonomy and independence available to young people in LMIC is likely to be heavily determined by family SES, more than in high-income countries. ${ }^{32}$ Finally, if equalisation is

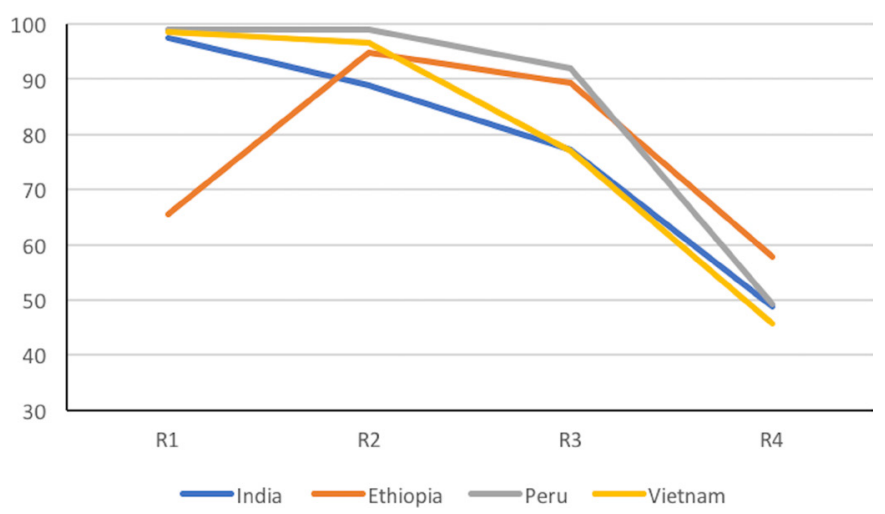

Figure 5 Percentage of each cohort currently in education by round.

thought to be driven by participation in secondary school, it is important to note the proportion of attendance in education among Young Lives cohorts is not comparable with high-income countries, falling sharply among the older adolescent age group to just above 50\% (figure 5). Further, among those in education, there will continue to be high levels of social segregation within schools and between them, further limiting opportunities for social mixing in LMIC. ${ }^{33}$

\section{CONCLUSION}

Health inequalities in late childhood persist during adolescence and into adulthood, and we have found no consistent pattern of reducing health gradients during adolescence. There is good evidence that socioeconomic disadvantage and poverty during the early life-course is associated with not only poorer health in childhood but also increased mortality and morbidity later in life, ${ }^{34}$ and that inequalities among adolescents are actually increasing over time.$^{35}$ Improving the health of adolescence in LMIC will bring multiple dividends to population health, ${ }^{13}$ and this study highlights the need to explore interventions to reduce health inequalities during this crucial stage of the life-course.

Acknowledgements The data used in this publication come from Young Lives, a 15-year survey investigating the changing nature of childhood poverty in Ethiopia, India (Andhra Pradesh), Peru and Vietnam, based at the University of Oxford (www.younglives.org.uk). Young Lives is core funded by the UK Department for International Development.

Contributors JLW and RMV contributed equally to study design/conception, performing the analysis, design of figures and writing the manuscript.

Funding The authors have not declared a specific grant for this research from any funding agency in the public, commercial or not-for-profit sectors.

Disclaimer The views expressed here are those of the authors and are not necessarily those of the Young Lives project, the University of Oxford, DFID or other funders.

Competing interests None declared.

Patient consent Not required.

Provenance and peer review Not commissioned; externally peer reviewed.

Data sharing statement Data used in this study are publicly available at www. younglives.org.uk. All authors had full access to all of the data (including statistical 
reports and tables) in the study and can take responsibility for the integrity of the data and the accuracy of the data analysis.

Open access This is an open access article distributed in accordance with the Creative Commons Attribution Non Commercial (CC BY-NC 4.0) license, which permits others to distribute, remix, adapt, build upon this work non-commercially, and license their derivative works on different terms, provided the original work is properly cited, appropriate credit is given, any changes made indicated, and the use is non-commercial. See: http://creativecommons.org/licenses/by-nc/4.0/.

\section{REFERENCES}

1. Marmot M. Fair society, healthy lives. Inequalities in health: Concepts, measures, and ethics, 2010:282.

2. Marmot M, Friel S, Bell R, et al. Closing the gap in a generation: health equity through action on the social determinants of health. The Lancet 2008;372:1661-9.

3. Currie C. Social determinants of health and well-being among young people. Denmark: World Health Organization Regional Office for Europe Copenhagen, 2012.

4. West P. Health inequalities in the early years: is there equalisation in youth? Soc Sci Med 1997;44:833-58.

5. Blane D, Bartley M, Smith GD, et al. Social patterning of medical mortality in youth and early adulthood. Soc Sci Med 1994;39:361-6.

6. Dibben C, Popham F. Are health inequalities evident at all ages? An ecological study of English mortality records. Eur J Public Health 2013:23:39-45.

7. Green MA. The equalisation hypothesis and changes in geographical inequalities of age based mortality in England, 2002-2004 to 20082010. Soc Sci Med 2013;87:93-8.

8. Spencer NJ. Social equalization in youth: evidence from a crosssectional British survey. Eur J Public Health 2006;16:368-75.

9. Wickrama KA, Noh S, Elder GH. An investigation of family SESbased inequalities in depressive symptoms from early adolescence to emerging adulthood. Adv Life Course Res 2009;14:147-61.

10. Vallejo-Torres L, Hale D, Morris S, et al. Income-related inequality in health and health-related behaviour: exploring the equalisation hypothesis. J Epidemiol Community Health 2014;68:615-21.

11. West $P$, Sweeting $H$. Evidence on equalisation in health in youth from the West of Scotland. Soc Sci Med 2004;59:13-27.

12. Gardner $M$, Steinberg L. Peer influence on risk taking, risk preference, and risky decision making in adolescence and adulthood: an experimental study. Dev Psychol 2005;41:625-35.

13. Patton GC, Sawyer SM, Santelli JS, et al. Our future: a Lancet commission on adolescent health and wellbeing. Lancet 2016;387:2423-78.

14. Viner RM, Ozer EM, Denny S, et al. Adolescence and the social determinants of health. Lancet 2012;379:1641-52

15. World Health Organization. Global health risks: mortality and burden of disease attributable to selected major risks: World Health Organization, 2009.

16. Ward JL, Harrison K, Viner RM, et al. Adolescent cohorts assessing growth, cardiovascular and cognitive outcomes in low and middleincome countries. PLoS One 2018;13:e0190443.
17. Young Lives: an International Study of Childhood Poverty: Round 4, 2013-2014 [Internet, 2016. UK Data Service SN 7931. http://doi.org/.

18. Barnett I, Ariana P, Petrou S, et al. Cohort profile: the Young Lives study. Int J Epidemiol 2013;42:701-8.

19. Briones K. 'How Many Rooms Are There in Your House' Constructing the Young Lives Wealth Index. Young LIves Technical Note 2017;43.

20. Young Lives Rounds 1 to 4 Constructed Files Technical Note 35 [Internet], 2016.

21. Emerson E, Graham H, Hatton C. Household income and health status in children and adolescents in Britain. Eur J Public Health 2006;16:354-60.

22. Moor I, Pförtner TK, Lampert T, et al. [Socioeconomic inequalities in subjective health among 11- to 15-year-olds in Germany. A trend analysis from 2002-2010]. Gesundheitswesen 2012;74 Suppl:S49-55.

23. Dinsa GD, Goryakin Y, Fumagalli E, et al. Obesity and socioeconomic status in developing countries: a systematic review. Obes Rev 2012;13:1067-79.

24. World Health Organization. Growing up unequal: Gender and socioeconomic differences in young people's health and well-being: Health policy for children and adolescents, 2016.

25. Hanson MD, Chen E. Socioeconomic status and health behaviors in adolescence: a review of the literature. J Behav Med 2007;30:263-85.

26. Dalstra JA, Kunst AE, Borrell C, et al. Socioeconomic differences in the prevalence of common chronic diseases: an overview of eight European countries. Int J Epidemiol 2005;34:316-26.

27. Matthews S, Manor O, Power C. Social inequalities in health: are there gender differences? Soc Sci Med 1999;48:49-60.

28. Howe LD, Galobardes B, Matijasevich A, et al. Measuring socioeconomic position for epidemiological studies in low- and middleincome countries: a methods of measurement in epidemiology paper Int J Epidemiol 2012;41:871-86.

29. Dornan P. Growth, wealth and inequality: evidence from Young Lives, 2011.

30. Currie C. Inequalities in young people's health: HBSC international report from the 2005/2006: Survey: World Health Organization, 2008.

31. Ward JL, Viner RM. The impact of income inequality and national wealth on child and adolescent mortality in low and middle-income countries. BMC Public Health 2017;17:429.

32. Council NR. Population Co. Growing up global: The changing transitions to adulthood in developing countries: National Academies Press, 2005.

33. Antoninis M. Global Education Monitoring Report 2017/18. Accountability in education: meeting our commitments. UNSECO 2017.

34. Galobardes B, Lynch JW, Davey Smith G. Childhood socioeconomic circumstances and cause-specific mortality in adulthood: systematic review and interpretation. Epidemiol Rev 2004;26:7-21.

35. Elgar FJ, Pförtner TK, Moor I, et al. Socioeconomic inequalities in adolescent health 2002-2010: a time-series analysis of 34 countries participating in the Health Behaviour in School-aged Children study. Lancet 2015;385:2088-95. 